\title{
Arduino Based Smart Power Meter: A Low-cost Approach for Academic and Research Applications
}

\author{
${ }^{a, c}$ Cristian D. Chiñas-Palacios, Carlos Vargas-Salgadob, Jesús Águila-León ${ }^{\text {a,c }}$, Elías \\ Hurtado-Pérez \\ a Departamento de Estudios del Agua y la Energía, Universidad de Guadalajara, México, \\ daniel.chinas@academicos.udg.mx, jesus.aguila@academicos.udg.mx, ${ }^{b}$ Departamento de Ingeniería \\ Eléctrica, Universitat Politècnica de València, Valencia, España, carvarsa@upvnet.upv.es, \\ ejhurtado@die.upv.es, ${ }^{\mathrm{c}}$ Instituto Universitario de Ingeniería Energética, Universitat Politècnica de \\ València, España, cricripa@upvnet.upv.es, carvarsa@upvnet.upv.es, jeagleo@upvnet.upv.es, \\ ejhurtado@die.upv.es.
}

\begin{abstract}
Energy consumption has increased significantly over the past century, which has brought several bad conditions for the environment. One way to reduce these adverse consequences of energy consumption from Earth is to make smarter and more efficient use of it, and measuring energy is an essential task to accomplish it. A detailed measurement of power consumption at nonindustrial level is often excessively expensive. This paper presents the design and implementation of an Arduino-based low-cost smart power meter, as an affordable alternative. An evaluation of the Arduino-based smart power meter performance is carried out by comparing its measurements against measurements obtained by a commercial Siemens SENTRON PAC3200 smart power meter. Results show that the Arduino-based smart power meter has similar accuracy to the commercial power meter, making it an interesting alternative for low-budget applications.
\end{abstract}

Keywords: Power meter; energy consumption; Arduino; low-cost monitoring.

\section{Introduction}

Nowadays, companies, industries, and small-scale electricity consumers seek to optimize costs to be more competitive in the market. To achieve cost savings, it is possible to act in many ways, including making smart electricity consumption (Abdelaziz, Saidur, \& Mekhilef, 2011). Power meters are devices that measure the power consumed, as well as other electrical parameters, such as voltage, current, and frequency. Power meters allows to 
know in detail the electrical consumption of industrial machines or appliances (Hirst, Miller, Kaplan, \& Reed, 2013), being able to monitor both three-phase systems and singlephase systems. Energy monitoring and measurement can be decisive for this goal. This monitoring can be carried from the smallest consumption to the generation itself through the transport and distribution of electrical energy and know the efficiency of the system, knowing the values of voltage, current, and electricity consumption (Uribe-Pérez, Hernández, de la Vega, \& Angulo, 2016).

The low-cost electric power meters that have been developed today have been minimal, focusing only on voltage and current measurements (Madalamootoo \& Shamachurn, 2018; Mnati, Van den Bossche, \& Chisab, 2017). Power factor (PF) is an essential electric parameter to measure and compensate if necessary, efforts have been made to develop PF compensators and dataloggers (Cano Ortega, Sánchez Sutil, \& De la Casa Hernández, 2019). Emphasis should be placed on the memory capacity of the microcontroller since the microcontroller is responsible for electrical parameters measurements collecting and power calculating, low-cost power meters developed are often Arduino-based due to its robustness and quick setup and implementation (Amiry et al., 2018).

This paper presents the design and implementation of a low-cost Arduino-based Power Meter (APM) to monitor the energy consumption in the microgrid at the Renewable Energies Laboratory at the Universitat Politècnica de València (LabDER-UPV), Spain. Furthermore, a comparative analysis between the APM prototype against a brand power meter is carried out.

\section{Methodology}

The development of the APM consists of a four-stage process, as shown in Figure 1. The first stage focused on the platform support, which was decided to be Arduino-based due to its low cost and versatility for a wide range of applications. The second stage focused on selecting the right sensors to perform current and voltage measurements, being as a requirement to be as contactless as possible. The third stage was the assembly and programming of the APM, for which Emonlib.h library, available on the www.openenergymonitor.org website, was used and modified for power calculations. Finally, the fourth stage focused on APM performance and reliability tests. 
Stage 1

- Platform choice

and preliminary

power meter

design.
Stage 2

- Sensors and power

meter electric

circuit design.

\section{Stage 3}

-Assemmbly and

programming of

the power meter prototype.

\section{Stage 4}

- Power meter

prototype

performance tests.

Fig. 1 Stages of the Arduino-based power meter implementation process.

\section{Arduino Power Meter system design}

One of the main requirements for the power meter is considering its robustness and reliability, along with a low-cost budget. The APM being based on a worldwide platform and using open source libraries allows easy implementation.

\subsection{APM characteristics}

The main features of the developed prototype are shown in Table 1. It is noteworthy that once the APM is installed, it will perform the measurements and save the history of them inside a microSD memory. The AMP is designed to operate in $220 \mathrm{~V} \mathrm{x} 50 \mathrm{~Hz}$ power grids, according to the European standard in force in Spain, if it is required to install in another type of electrical grid it would be necessary to make adaptations to the electrical circuit of the APM.

Table 1 APM main features.

\begin{tabular}{|l|c|c|}
\hline Description & Units & Measurement range \\
\hline Input voltage & $220 \mathrm{~V} \mathrm{@} \mathrm{50} \mathrm{Hz}$ & - \\
\hline RMS voltage & $\mathrm{V}$ & $9-220 \mathrm{~V}$ \\
\hline RMS current & $\mathrm{A}$ & $0-100 \mathrm{~A}$ \\
\hline Frequency & $\mathrm{Hz}$ & $0-50 \mathrm{~Hz}$ \\
\hline Real power & $\mathrm{W}$ & - \\
\hline Apparent power & $\mathrm{VA}$ & - \\
\hline Reactive power & $\mathrm{VAr}$ & - \\
\hline Power factor & - & $0-1$ \\
\hline
\end{tabular}




\subsection{Calibration Tests}

Before testing the microgrid and once the APM prototype was assembled, a calibration process was necessary. The calibration process was based on adjusting the power factor measurement made by the APM under known conditions, in this case, using a resistive load in such a way that the power factor returned by the APM must be equal to 1, given the characteristics of the load. Figure 2 shows one of the first calibration tests performed for the APM. The adjustment of the power factor measurement is made employing constant adjustment within the Emonlib.h library responsible for implementing the power factor based on instant voltage and current measurements and the zero-crossing detection method.

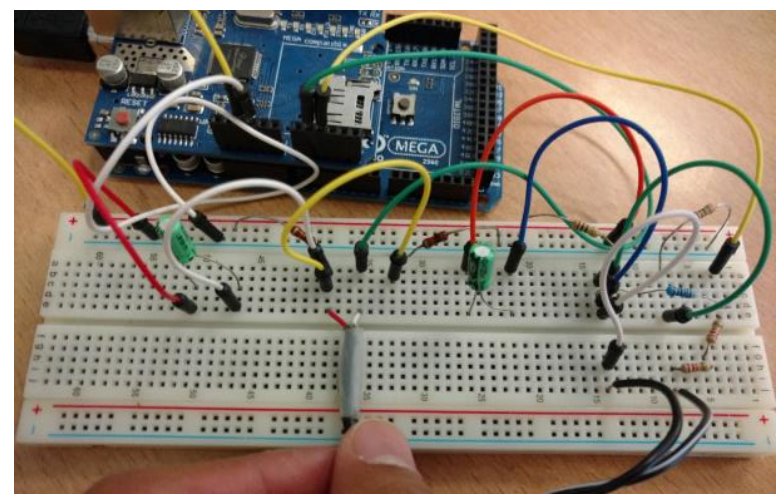

Fig. 2 Arduino-based power meter calibration test.

\section{Results}

As a result of the methodology shown, a low-cost power meter based on Arduino was obtained, capable of performing measurements of current, voltage, active, reactive, and apparent power, as well as power factor and frequency in single-phase electrical networks. Figure 3a shows the prototype of the APM by integrating a display to show the measurements in real-time, while Fig. 3 b shows its connection diagram. 


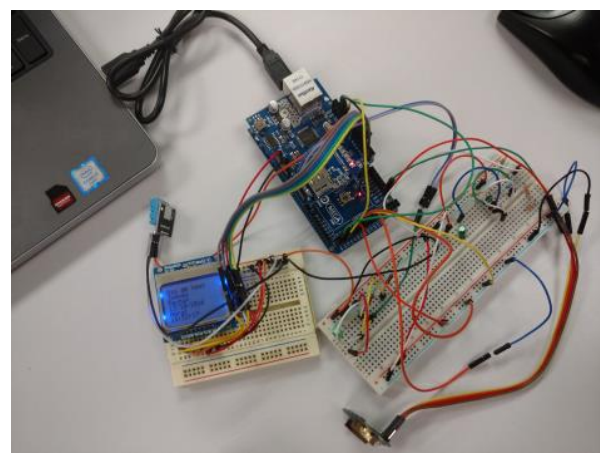

(a)

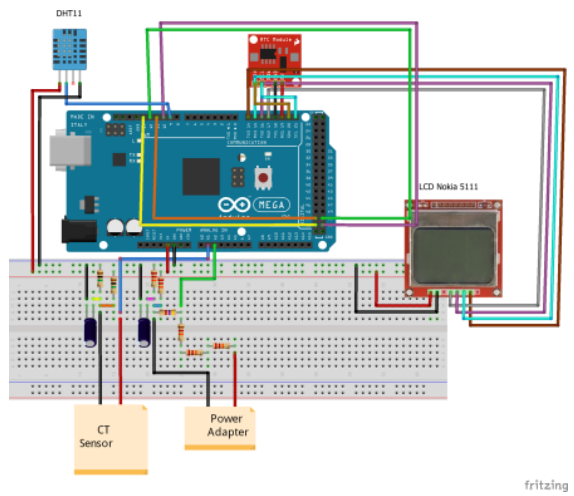

(b)

Fig. 3 (a) Arduino-based power meter prototype and (b) Schematic diagram of components connection.

\subsection{Tests Results}

Once the prototype was assembled and calibrated, operational tests were carried out in a real application environment at the UPV Renewable Energy Laboratory (LabDER-UPV). Figure $4 \mathrm{a}$ shows the data set obtained from the microSD and imported to Microsoft Excel after an experimental test performed on the microgrid; Figure $4 \mathrm{~b}$ shows measurement curves for real power, apparent power, and reactive power inside de microgrid.

After validating the operation of the prototype, it was compared against measurements made by a Siemens brand power meter, Sentron PAC3200 model, under the same conditions. Table 2 shows the comparison of the measurement of electrical parameters of both devices for average values after operational tests.

Table 2 Power measurement comparison between APM and Siemens Sentron PAC3200.

\begin{tabular}{|ccc|}
\hline Apparent power (kW) & $\mathbf{8 . 3 6}$ & $\mathbf{8 . 3 3}$ \\
\hline Voltage (V) & 227.50 & 229.23 \\
\hline Electrical current (A) & 3.67 & 3.63 \\
\hline Power Factor & 0.93 & 0.95 \\
\hline Frequency (Hz) & 50.15 & 50.10 \\
\hline
\end{tabular}




\begin{tabular}{|c|c|c|c|c|c|c|c|c|c|c|}
\hline \multirow{2}{*}{\multicolumn{2}{|c|}{ 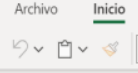 }} & \multirow[t]{2}{*}{ Insertar } & Fórmulas & \multirow{2}{*}{$\begin{array}{l}\text { Datos } \\
\mathrm{N}\end{array}$} & \multirow{2}{*}{$\begin{array}{c}\text { Revisar Vista } \\
\text { A } A-A\end{array}$} & Ayuda & \multicolumn{2}{|c|}{ Abrir en la aplicación de escritorio } & \multicolumn{2}{|c|}{ Q ¿Qué desea hacer? } \\
\hline & & & $v 12$ & & & $\cdots$ & 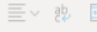 & 19. General & $\$>\$ 00=00$ & 四、间 \\
\hline$F 21$ & $f f$ & 1950,25 & & & & & & & & \\
\hline 4 & A & B & c & D & E & & $\mathbf{F}$ & G & H & 1 \\
\hline 1 & Fecha & Hora & Voltaje (V) & $\begin{array}{c}\text { Corriente } \\
\text { (A) }\end{array}$ & $\begin{array}{c}\text { Potencia Real } \\
\text { (W) }\end{array}$ & Poten & $\begin{array}{l}\text { cia Aparente } \\
\text { (VA) }\end{array}$ & $\begin{array}{c}\text { Potencia Reactiva } \\
\text { (Var) }\end{array}$ & Factor de Potencia & $\begin{array}{c}\text { Frecuencia } \\
(\mathrm{Hz})\end{array}$ \\
\hline 2 & $28 / 12 / 2016$ & $14: 13$ & 232,31 & 8,48 & \begin{tabular}{|l|}
1808,37 \\
\end{tabular} & & 1970,97 & 783,89 & 0,92 & 48,08 \\
\hline 3 & $28 / 12 / 2016$ & $14: 13$ & 231,94 & 8,59 & 1833,04 & & 1993,12 & 782,63 & 0,92 & 48,17 \\
\hline 4 & $28 / 12 / 2016$ & $14: 13$ & 231,29 & 8,53 & 1821,07 & & 1972,53 & 758,01 & 0,92 & 46,3 \\
\hline 5 & $28 / 12 / 2016$ & $14: 13$ & 230,32 & 8,48 & 1799,2 & & 1954,05 & 762,35 & 0,92 & 48,17 \\
\hline 6 & 28/12/2016 & $14: 13$ & 230,16 & 8,48 & 1799,82 & & 1952,68 & 757,39 & 0,92 & 49,12 \\
\hline 7 & 28/12/2016 & $14: 13$ & 230,08 & 8,55 & 1814,78 & & 1968,26 & 761,98 & 0,92 & 48,08 \\
\hline 8 & 28/12/2016 & $14: 13$ & 229,78 & 8,5 & 1799,77 & & 1953,49 & 759,58 & 0,92 & 48,08 \\
\hline 9 & $28 / 12 / 2016$ & $14: 13$ & 230,2 & 8,57 & 1817,84 & & 1972,51 & 765,68 & 0,92 & 49,02 \\
\hline 10 & 28/12/2016 & $14: 13$ & 230,75 & 8,52 & 1811,59 & & 1965,15 & 761,53 & 0,92 & 49,02 \\
\hline 11 & 28/12/2016 & $14: 13$ & 231,62 & 8,55 & 1830,39 & & 1979,84 & 754,61 & 0,92 & 50 \\
\hline 12 & $28 / 12 / 2016$ & $14: 13$ & 230,15 & 8,52 & 1806,62 & & 1959,82 & 759,6 & 0,92 & 49,12 \\
\hline 13 & 28/12/2016 & $14: 13$ & 229,18 & 8,49 & 1797,03 & & 1945,78 & 746,15 & 0,92 & 50,2 \\
\hline 14 & 28/12/2016 & $14: 13$ & 231 & 8,56 & 1824,5 & & 1977,93 & 763,81 & 0,92 & 49,02 \\
\hline 15 & $28 / 12 / 2016$ & $14: 32$ & 230,74 & 8,47 & 1802,55 & & 1954,89 & 756,58 & 0,92 & 50,1 \\
\hline 16 & $28 / 12 / 2016$ & $14: 32$ & 230,61 & 8,38 & 1776,83 & & 1932,04 & 758,73 & 0,92 & 49,12 \\
\hline 17 & 28/12/2016 & 14:32 & 230,33 & 8,35 & 1769,72 & & 1924,32 & 755,71 & 0,92 & 50 \\
\hline 18 & $28 / 12 / 2016$ & $14: 32$ & 230,7 & 8,4 & 1783,82 & & 1938,02 & 757,56 & 0,92 & 50 \\
\hline 19 & $28 / 12 / 2016$ & $14: 32$ & 230,29 & 8,37 & 1772,29 & & 1927,36 & 757,44 & 0,92 & 49,9 \\
\hline 20 & $28 / 12 / 2016$ & $14: 32$ & 229,42 & 8,34 & 1760,03 & & 1913,66 & 751,24 & 0,92 & 50 \\
\hline 21 & $28 / 12 / 2016$ & $14: 32$ & 230,48 & 8,46 & 1793,33 & & 1950,25 & 766,45 & 0,92 & 50 \\
\hline 22 & $28 / 12 / 2016$ & $14: 32$ & 230,21 & 8,49 & 1804,94 & & 1955,31 & 751,94 & 0,92 & 50 \\
\hline 23 & $28 / 12 / 2016$ & $14: 32$ & 230,41 & 8,35 & 1773,63 & & 1924,34 & 746,53 & 0,92 & 50 \\
\hline 24 & 28/12/2016 & $14: 32$ & 230,63 & 8,38 & 1780,21 & & 1933 & 753,22 & 0,92 & 50 \\
\hline 25 & $28 / 12 / 2016$ & $14: 32$ & 230,36 & 8,39 & 1782,59 & & 1933,73 & 749,45 & 0,92 & 49,9 \\
\hline 26 & $28 / 12 / 2016$ & $14: 32$ & 230,37 & 8,35 & 1773,81 & & 1923,84 & 744,8 & 0,92 & 50,1 \\
\hline
\end{tabular}

(a)

\section{MEASUREMENTS OF THE APM DURING A 15-MIN \\ TEST}

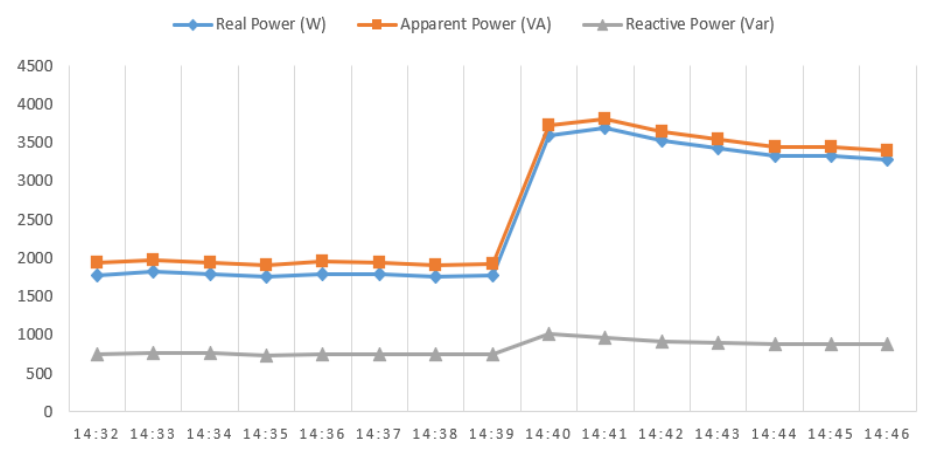

(b)

Fig.4 Results of the APM measurement tests: (a) Data records imported to MS Excel from the APM microSD card; (b) Energy consumption from active, reactive, and apparent power measurements.

\subsection{Cost}

As mentioned above, an essential part of the developed APM prototype is that it is a lowcost device. Table 3 shows the price list of the APM components involved in the construction of the Arduino-based power meter prototype. Compared to a professional 
power meter, the APM implementation is cheaper, functional, and worthy, by considering locations where acquiring a sophisticated power meter can be expensive.

Table 3 APM main features.

\begin{tabular}{|c|c|}
\hline Device & Total Cost \\
\hline Arduino MEGA 2560 board & $21,40 €$ \\
\hline Nokia 5110 screen compatible with Arduino & $5,75 €$ \\
\hline DHT11 humidity and temperature sensor & $3,50 €$ \\
\hline Arduino Ethernet Shield W5100 & $9,99 €$ \\
\hline Real-Time Clock DS3231 & $5,79 €$ \\
\hline AC-AC transformer VB 2,3/2/12 230VAC-12VAC & $5,99 €$ \\
\hline Non-intrusive current sensor SCT-013-000 & $12,08 €$ \\
\hline 2x1 M $\Omega, 2 \times 22 \mathrm{k} \Omega, 3 \times 10 \mathrm{k} \Omega$ Resistors & $1,19 €$ \\
\hline $10 \mu \mathrm{Fa}-25 \mathrm{~V}$ electrolitic capacitors & $1,01 €$ \\
\hline Arduino ProtoShield extension & $9,15 €$ \\
\hline APM prototype & $75,85 €$ \\
\hline Sentron PAC3200 & $428,79 €$ \\
\hline
\end{tabular}

* Prices are approximated and may vary due to different locations.

\section{Conclusions}

This work presented the development and operational functional testing of an Arduinobased low-cost power meter prototype. The implemented APM measures RMS voltage, RMS current, active, reactive, and apparent power, frequency, and power factor of the electrical grid. Measurements are stored on a microSD card within the Arduino Ethernet Shield for further retrieval and analysis.

The APM will help and provide valuable information about monitoring the energy consumption, using low-cost devices in the prototype implementation, for the visualization of measurement parameters in an LCD. The significant achievements reached were:

- $\quad$ Economical and reliable alternative to measuring electrical energy parameters.

- $\quad$ Real-time data monitoring and measurements data storage.

- $\quad$ Cheap budget solutions for energy monitoring systems with validated data.

\section{Acknowledgments}

The authors gratefully acknowledge to the Universitat Politècnica de València and the Instituto Universitario de Ingeniería Energética for their support to accomplish this work. 


\section{References}

Abdelaziz, E. A., Saidur, R., \& Mekhilef, S. (2011, January 1st). A review on energy saving strategies in industrial sector. Renewable and Sustainable Energy Reviews. Pergamon. https://doi.org/10.1016/j.rser.2010.09.003

Amiry, H., Benhmida, M., Bendaoud, R., Hajjaj, C., Bounouar, S., Yadir, S., ... Sidki, M. (2018). Design and implementation of a photovoltaic I-V curve tracer: Solar modules characterization under real operating conditions. Energy Conversion and Management, 169, 206-216. https://doi.org/10.1016/j.enconman.2018.05.046

Cano Ortega, A., Sánchez Sutil, F. J., \& De la Casa Hernández, J. (2019). Power Factor Compensation Using Teaching Learning Based Optimization and Monitoring System by Cloud Data Logger. Sensors, 19(9), 2172. https://doi.org/10.3390/s19092172

Hirst, J. M., Miller, J. R., Kaplan, B. A., \& Reed, D. D. (2013). Watts Up? Pro AC Power Meter for Automated Energy Recording. Behavior Analysis in Practice, 6(1), 82-95. https://doi.org/10.1007/bf03391795

Madalamootoo, L., \& Shamachurn, H. (2018). Experimental Performance Assessment of a low-cost single-phase Arduino-based Power Meter, 7(1), 1-7.

Mnati, M., Van den Bossche, A., \& Chisab, R. (2017). A Smart Voltage and Current Monitoring System for Three Phase Inverters Using an Android Smartphone Application. Sensors, 17(4), 872. https://doi.org/10.3390/s17040872

Uribe-Pérez, N., Hernández, L., de la Vega, D., \& Angulo, I. (2016). State of the Art and Trends Review of Smart Metering in Electricity Grids. Applied Sciences, 6(3), 68. https://doi.org/10.3390/app6030068 